Article

\title{
Associations between Vitamin B-12 Status and Oxidative Stress and Inflammation in Diabetic Vegetarians and Omnivores
}

\author{
Yau-Jiunn Lee ${ }^{1}$, Ming-Yang Wang ${ }^{2}$, Mon-Chiou Lin ${ }^{3}$ and Ping-Ting Lin ${ }^{4,5, *}$ \\ 1 Lee's Endocrinologic Clinic, Pingtung 90000, Taiwan; t3275@ms25.hinet.net \\ 2 Department of Nutrition, Jen-Ai Hospital, Tali-Taichung 40201, Taiwan; steady9705@gmail.com \\ 3 Department of Dietetics \& Nutrition, Yang Ming Hospital, Chiayi 60045, Taiwan; a0912132648@gmail.com \\ 4 School of Nutrition, Chung Shan Medical University, Taichung 40201, Taiwan \\ 5 Department of Nutrition, Chung Shan Medical University Hospital, Taichung 40201, Taiwan \\ * Correspondence: apt810@csmu.edu.tw; Tel.: +886-4-2473-0022 (ext. 12187); Fax: +886-4-2324-8175
}

Received: 11 January 2016; Accepted: 19 February 2016; Published: 26 February 2016

\begin{abstract}
Diabetes is considered an oxidative stress and a chronic inflammatory disease. The purpose of this study was to investigate the correlations between vitamin B-12 status and oxidative stress and inflammation in diabetic vegetarians and omnivores. We enrolled 154 patients with type 2 diabetes (54 vegetarians and 100 omnivores). Levels of fasting glucose, glycohemoglobin (HbA1c), lipid profiles, oxidative stress, antioxidant enzymes activity, and inflammatory makers were measured. Diabetic vegetarians with higher levels of vitamin B-12 (>250 pmol/L) had significantly lower levels of fasting glucose, $\mathrm{HbA} 1 \mathrm{c}$ and higher antioxidant enzyme activity (catalase) than those with lower levels of vitamin B-12 ( $\leqslant 250 \mathrm{pmol} / \mathrm{L})$. A significant association was found between vitamin B-12 status and fasting glucose $(r=-0.17, p=0.03), \mathrm{HbA} 1 \mathrm{c}(r=-0.33, p=0.02)$, oxidative stress (oxidized low density lipoprotein-cholesterol, $r=-0.19, p=0.03$ ), and antioxidant enzyme activity (catalase, $r=0.28, p=0.01$ ) in the diabetic vegetarians; vitamin B-12 status was significantly correlated with inflammatory markers (interleukin-6, $r=-0.33, p<0.01$ ) in diabetic omnivores. As a result, we suggest that it is necessary to monitor the levels of vitamin B-12 in patients with diabetes, particularly those adhering to a vegetarian diet.
\end{abstract}

Keywords: vitamin B-12; oxidative stress; inflammation; vegetarian; diabetes

\section{Introduction}

Data from the Third National Health and Nutrition Examination Survey (NHANES III) indicated that an overall estimated US adult population prevalence of low serum vitamin B- 12 status was $3.2 \%$, and the prevalence increased to $4.4 \%$ for those aged $>50$ years [1]. It is well known that a vegetarian diet may influence the vitamin B-12 status because vitamin B-12 is present in most animal food sources, and the low status of vitamin B-12 among vegetarians that results in hyperhomocysteinemia, elevated red blood cell distribution width and mean corpuscular volume predisposes one to circulatory problems, and may negate the health benefits of the vegetarian diet [2]. Metformin is considered a cornerstone in the treatment of diabetes; it not only showed a beneficial effect on reducing levels of plasma glucose but also on lowering lipids profiles [3]. However, data from NHANES 1999-2006 found the prevalence of vitamin B-12 deficiency to be $5.8 \%$ in US adults with diabetes under metformin therapy [4] and therefore suggest that long-term treatment of diabetic patients with metformin may cause a higher risk of developing vitamin B-12 deficiency [5].

Diabetes is considered an oxidative stress and a chronic inflammatory disease [6]. Recent studies have indicated that vitamin B-12 is an antioxidant, and a lower status of vitamin B-12 might be a 
potential trigger contributing to increase oxidative stress, particularly in patients with diabetes [7-9]. Vitamin B-12 acts as an antioxidant or anti-inflammation agent, which might modulate oxidative stress responses, including those of inflammatory responses [10-14]. To the best of our knowledge, no clinical study has examined the association between vitamin B-12 status and oxidative stress and inflammation, especially in patients with diabetes who adhere to a vegetarian diet. Therefore, the purpose of this study was to investigate the correlations between vitamin B-12 status and oxidative stress, and inflammation in diabetic vegetarians and omnivores.

\section{Materials and Methods}

\subsection{Study Design}

The current study was a cross-sectional study. We enrolled 154 (64 male and 93 female) adult patients (aged 20-84 years) with type 2 diabetes from Lee's Endocrinologic Clinic (Pingtung County, Taiwan). The diagnostic criteria for type 2 diabetes were defined as a glycohemoglobin $(\mathrm{HbA} 1 \mathrm{c}) \geqslant 6.5 \%$, a fasting glucose $\geqslant 7.0 \mathrm{mmol} / \mathrm{L}$ or a 2 -h plasma glucose $\geqslant 11 \mathrm{mmol} / \mathrm{L}$ during an oral glucose tolerance test (OGTT), as well as the use of anti-hyperglycemic drugs. We excluded patients with liver or renal disease, pregnant women, and using antioxidants or vitamin B-12 supplements. The inclusion criteria for vegetarian subjects were that the subjects consumed no meat or fish, although they were allowed to consume dairy products or eggs, and had maintained a vegetarian diet for at least one year. Fifty-four diabetic vegetarians and 100 omnivores participated in this study. The study was approved by the Institutional Review Board of Chung Shan Medical University Hospital, Taiwan (CSMUH No.: CS12203). Each subject provided written informed consent to participate in the study.

\subsection{Anthropometric and Dietary Measurements}

We measured blood pressures, body weights, heights, and waist and hip circumferences of each patient, and then calculated the body mass index (BMI) and ratios of waist to hip circumference. Blood pressure was measured after each patient rested for at least $5 \mathrm{~min}$. Dietary intake was assessed by dietitians and used 24-h diet recall. The data of nutrients were analyzed using the Nutritionist Professional software package (E-Kitchen Business Corp., Taiwan). The ages, gender, smoking, drinking, exercise habits, and medications of all subjects were recorded.

\subsection{Blood Collection and Biochemical Measurement}

Fasting blood specimens were collected in vacutainer tubes without anticoagulant (Becton Dickinson, Rutherford, NJ, USA). The samples were centrifuged at $3000 \mathrm{rpm}$ for $15 \mathrm{~min}$ at $4{ }^{\circ} \mathrm{C}$ and the serum was separated. Fasting glucose was measured by Roche Performa glucose meters (Accu-chek, Mannheim, Germany) and glycohemoglobin ( $\mathrm{HbA1c}$ ) was measured by Variant II hemoglobin testing system kits (Bio-Rad Laboratories, Inc., California, CA, USA). Serum total cholesterol (TC), triglyceride (TG), low density lipoprotein-cholesterol (LDL-C), and high density lipoprotein-cholesterol (HDL-C) levels were measured using an automated biochemical analyzer (Hitachi-7180E, Tokyo, Japan). The levels of apolipoprotein A-1 (Apo-A1) and apolipoprotein-B (Apo-B) were measured using polyethylene glycerol (PEG) enhanced immunoturbidimetric assays (Siemens Healthcare Diagnostics Inc., New York, NY, USA).

\subsection{Serum Vitamin B-12, Oxidative Stress, and Inflammatory Markers Measurements}

Serum levels of vitamin B-12 were measured by electrochemiluminescence immunoassay (ECLIA) using a commercially available kit (Cobas ${ }^{\circledR}$ Roche, Basel, Switzerland). Serum oxidized LDL-C (Ox-LDL-C) was measured by an enzyme-linked immunosorbent assay (ELISA) using a commercially available kit (Mercodia, Uppsala, Sweden) according to the supplier's instructions. Plasma malondialdehyde (MDA) was determined using the thiobarbituric acid reactive substances method, as described by Botsoglou et al. [15]. Red blood cells (RBCs) were diluted with 25x sodium 
phosphate buffer for superoxide dismutase (SOD) and glutathione peroxidase (GPx) measurements and 250x sodium phosphate buffer for catalase (CAT) measurement. The methods for measuring CAT, SOD, and GPx in RBCs have been previously described [16-18]; these measurements were performed spectrophotometrically at $240 \mathrm{~nm}, 325 \mathrm{~nm}$, and $340 \mathrm{~nm}$, respectively. Protein contents of RBCs were determined based on the Biuret reaction of the BCA kit (Thermo, Rockford, IL, USA). Antioxidant enzymes activity levels were expressed as unit/mg of protein. All analyses were performed in duplicate and the variations of repeated determinations were within $5 \%$ of the same sample. With regard to the inflammatory markers, serum levels of high sensitivity C-reactive protein (hs-CRP) were quantified by particle-enhanced immunonephelometry with an image analyzer (Dade Behring, Deerfield, IL, USA), and serum levels of high sensitivity interleukin-6 (IL-6) were measured by ELISA using a commercially available kit (eBioscience, San Diego, CA, USA).

\subsection{Statistical Analysis}

The data were expressed as the means and standard deviations (SD), as well as the medians. A Kolmogorov-Smirnov test was used to examine the normal distribution of variables. Student's $t$-test or the Mann-Whitney rank sum test was used to compare mean values for continuous variables between the diabetic vegetarians and omnivores. For the categorical response variables, differences between the two groups were assessed by the Chi-square test or Fisher's exact test. Pearson product moment correlations or Spearman's rank order correlations were used to examine the correlation between serum vitamin B-12 status (a dummy variable of 1 was set for subjects who had higher levels of vitamin B-12; the variable for lower levels of vitamin B-12 was set at 0 ) and the levels of blood glucose, oxidative stress, and inflammatory markers. Multiple linear regressions were used to examine the correlations between serum vitamin B-12 status (as an independent variable) and blood glucose, oxidative stress, and inflammatory markers after adjustment for gender and age. The cut-off point of serum vitamin B-12 was set at $250 \mathrm{pmol} / \mathrm{L}$ based on the medians of vegetarians and the definition of vitamin B12 deficiency $(<150 \mathrm{pmol} / \mathrm{L})$ and borderline deficiency $(<200 \mathrm{pmol} / \mathrm{L})$ were according on Pawlak [2]. Statistical significance was set at $p<0.05$. All statistical analyses were performed using SigmaPlot software (version 12.0, Systat, San Jose, CA, USA).

\section{Results}

\subsection{Characteristics and Dietary Intake of Subjects}

The characteristics and dietary intake of the subjects are shown in Table 1 . The means for age $(p<0.01)$ were significantly higher in the diabetic vegetarians than in the omnivores. The diabetic vegetarians had a significantly lower frequency under the metformin $(p=0.02)$ or statin $(p<0.01)$ therapy and lower levels of FG $(p=0.06)$, TC $(p=0.07)$, and HDL-C $(p=0.01)$ than diabetic omnivores. However, the levels of TG ( $p=0.03)$, hs-CRP $(p=0.01)$, and IL-6 $(p=0.04)$ were significantly higher in diabetic vegetarians than in omnivores. Regarding the dietary intake, the diabetic vegetarians had significantly lower values of energy $(p<0.01)$, protein $(p<0.01)$, fat $(p<0.01)$, cholesterol $(p<0.01)$, and vitamin B-12 $(p<0.01)$ intake than the omnivores, even energy adjusted.

\subsection{Levels of Vitamin B-12 in the Diabetic Vegetarians and Omnivores}

The levels of vitamin B-12 in the diabetic vegetarians and omnivores are shown in Table 2. The diabetic vegetarians had significantly lower levels of vitamin B-12 than the omnivores $(p<0.01)$ as well as those under metformin $(p<0.01)$ or statin $(p<0.01)$ therapy. There was a significantly higher prevalence of vitamin B-12 deficiency in the diabetic vegetarians than in the omnivores. However, the level of vitamin B-12 was not significantly different between males and females, old and young subjects in both vegetarians and omnivores groups. 
Table 1. Basic characteristics and dietary intake of subjects.

\begin{tabular}{|c|c|c|c|}
\hline & Vegetarians $(n=54)$ & Omnivores $(n=100)$ & $p$ Values \\
\hline females $(n, \%)$ & $38(70 \%)$ & $55(55 \%)$ & 0.09 \\
\hline age (years) & $65.1 \pm 11.3(63.5)^{1}$ & $57.7 \pm 10.5(60.0)$ & $<0.01$ \\
\hline duration of diabetes (years) & $12.0 \pm 8.8(9.5)$ & $9.4 \pm 6.1(8.0)$ & 0.16 \\
\hline body weight $(\mathrm{kg})$ & $62.0 \pm 12.6(59.8)$ & $67.6 \pm 14.7(65.5)$ & 0.05 \\
\hline body mass index $\left(\mathrm{kg} / \mathrm{m}^{2}\right)$ & $24.9 \pm 6.2(25.5)$ & $26.5 \pm 5.7(25.5)$ & 0.31 \\
\hline waist circumference $(\mathrm{cm})$ & $88.0 \pm 9.9(89.3)$ & $88.1 \pm 11.7(86.5)$ & 0.63 \\
\hline hip circumference $(\mathrm{cm})$ & $95.1 \pm 8.0(94.5)$ & $97.3 \pm 10.3(96.0)$ & 0.32 \\
\hline waist to hip ratio & $0.95 \pm 0.15(0.90)$ & $0.92 \pm 0.13(0.90)$ & 0.45 \\
\hline physical activity $^{2}$ & $34(63 \%)$ & $67(67 \%)$ & 0.23 \\
\hline Metformin therapy $(n, \%)$ & $39(72 \%)$ & $89(89 \%)$ & 0.02 \\
\hline Statin therapy $(n, \%)$ & $26(48 \%)$ & $71(71 \%)$ & $<0.01$ \\
\hline Metformin + Statin $(n, \%)$ & $21(39 \%)$ & $64(64 \%)$ & $<0.01$ \\
\hline fasting glucose (mmol/L) & $7.3 \pm 0.9(6.7)$ & $7.7 \pm 2.1(7.4)$ & 0.06 \\
\hline $\mathrm{HbA} 1 \mathrm{c}(\%)$ & $7.4 \pm 1.2(7.2)$ & $7.7 \pm 1.3(7.6)$ & 0.30 \\
\hline TC (mmol/L) & $4.4 \pm 0.8(4.3)$ & $4.6 \pm 0.8(4.6)$ & 0.07 \\
\hline TG (mmol/L) & $1.6 \pm 1.3(1.3)$ & $1.4 \pm 1.4(1.1)$ & 0.03 \\
\hline LDL-C (mmol/L) & $2.3 \pm 0.6(2.3)$ & $2.4 \pm 0.6(2.3)$ & 0.26 \\
\hline HDL-C (mmol/L) & $1.3 \pm 1.2(1.2)$ & $1.4 \pm 0.3(1.4)$ & 0.01 \\
\hline TC/HDL-C & $3.6 \pm 1.1(3.4)$ & $3.4 \pm 1.0(3.1)$ & 0.13 \\
\hline Apo-A1 (g/L) & $1.3 \pm 0.3(1.3)$ & $1.2 \pm 0.3(1.2)$ & 0.36 \\
\hline Apo-B $(\mathrm{g} / \mathrm{L})$ & $0.8 \pm 0.2(0.8)$ & $0.8 \pm 0.2(0.8)$ & 0.77 \\
\hline hs-CRP (mg/L) & $2.1 \pm 2.6(1.1)$ & $1.5 \pm 1.9(0.8)$ & 0.01 \\
\hline IL-6 (pg/mL) & $2.5 \pm 1.9(1.8)$ & $2.0 \pm 1.7(1.5)$ & 0.04 \\
\hline \multicolumn{4}{|c|}{ Dietary intake } \\
\hline energy (kcal/day) & $1410.0 \pm 355.7(1380.6)$ & $1678.1 \pm 478.4(1621.9)$ & $<0.01$ \\
\hline protein (g/day) & $45.6 \pm 16.7(43.1)$ & $64.4 \pm 23.2(60.0)$ & $<0.01$ \\
\hline protein (g/kcal) & $1.98 \pm 3.25(1.57)$ & $1.47 \pm 0.17(1.46)$ & 0.04 \\
\hline$\%$ of total calories & $12.7 \% \pm 3.1 \%(12.8 \%)$ & $15.4 \% \pm 3.5 \%(14.9 \%)$ & $<0.01$ \\
\hline fat (g/day) & $38.0 \pm 16.1(36.5)$ & $58.7 \pm 26.3(55.0)$ & $<0.01$ \\
\hline fat (g/kcal) & $0.79 \pm 1.20(0.60)$ & $0.89 \pm 0.38(0.86)$ & $<0.01$ \\
\hline$\%$ of total calories & $24.0 \% \pm 8.1 \%(23.1 \%)$ & $31.0 \% \pm 10.1 \%(33.0 \%)$ & $<0.01$ \\
\hline carbohydrate (g/day) & $226.1 \pm 68.2(205.7)$ & $225.0 \pm 74.0(217.6)$ & 0.97 \\
\hline carbohydrate (g/kcal) & $4.53 \pm 6.26(3.59)$ & $3.43 \pm 1.21(3.37)$ & 0.13 \\
\hline$\%$ of total calories & $63.3 \% \pm 9.4 \%(62.1 \%)$ & $53.9 \% \pm 10.5 \%(52.9 \%)$ & $<0.01$ \\
\hline cholesterol (mg/day) & $50.9 \pm 96.0(1.7)$ & $208.5 \pm 158.0(155.3)$ & $<0.01$ \\
\hline cholesterol (mg/kcal) & $2.57 \pm 13.99(0.02)$ & $3.19 \pm 2.48(2.42)$ & $<0.01$ \\
\hline vitamin B-12 ( $\mu \mathrm{g} /$ day $)$ & $0.4 \pm 0.6(0.2)$ & $5.5 \pm 9.3(2.9)$ & $<0.01$ \\
\hline vitamin B-12 ( $\mu \mathrm{g} / \mathrm{kcal})$ & $0.02 \pm 0.07(0.003)$ & $0.08 \pm 0.14(0.049)$ & $<0.01$ \\
\hline
\end{tabular}

${ }^{1}$ mean $\pm \mathrm{SD}$ (medians); ${ }^{2}$ physical activity: individual exercise at least 3 times every week.

\subsection{Levels of Metabolic Biomarkers after Stratifying by Serum Vitamin B-12}

The levels of metabolic biomarkers after stratifying by serum vitamin B-12 are shown in Table 3 . With regard to the levels of blood glucose, diabetic vegetarians with higher levels of vitamin B-12 had significantly lower levels of fasting glucose and $\mathrm{HbA} 1 \mathrm{c}$ than those with lower levels of vitamin B-12 (fasting glucose, $p<0.05 ; \mathrm{HbA1c}, p=0.02$ ) and omnivores (fasting glucose, $p=0.01$; HbA1c, $p=0.04$ ). With regard to lipids profiles, diabetic omnivores with higher levels of vitamin B-12 had significantly higher levels of TC (TC, $p=0.02$ ) and LDL-C (LDL-C, $p=0.03$ ) than those with lower levels of vitamin B-12. Diabetic omnivores with higher levels of vitamin B-12 had significantly higher levels of HDL-C $(p=0.04)$ than vegetarians. 
Table 2. Serum vitamin B-12 in diabetic vegetarians and omnivores.

\begin{tabular}{|c|c|c|c|}
\hline & Vegetarians $(n=54)$ & Omnivores $(n=100)$ & $p$ Values $^{2}$ \\
\hline Serum vitamin B-12 (pmol/L) & $379.4 \pm 333.0(266.1)^{1}$ & $497.9 \pm 292.7(416.9)$ & $<0.01$ \\
\hline Males & $(n=16) 342.8 \pm 339.3(265.7)$ & $(n=45) 456.4 \pm 294.9(356.6)$ & 0.02 \\
\hline Females & $(n=38) 394.8 \pm 333.7(271.3)$ & $(n=55) 531.9 \pm 289.1(480.1)$ & $<0.01$ \\
\hline$p$ values $^{3}$ & $0 . \overline{58}$ & $0 . \overline{10}$ & \\
\hline Age $\geqslant 65$ years & $(n=26) 333.4 \pm 197.9(283.4)$ & $(n=20) 469.2 \pm 309.1(362.2)$ & $<0.05$ \\
\hline Age $<65$ years & $(n=28) 340.6 \pm 302.9(235.1)$ & $(n=80) 505.1 \pm 290.0(421.4)$ & $<0.01$ \\
\hline$p$ values ${ }^{3}$ & 0.55 & 0.42 & \\
\hline Vitamin B-12 deficiency ${ }^{4}(n, \%)$ & $10(18.5 \%)$ & $5(5.0 \%)$ & 0.02 \\
\hline $\begin{array}{l}\text { Vitamin B-12 borderline } \\
\text { deficiency }{ }^{4}(n, \%)\end{array}$ & $18(33.3 \%)$ & $7(7.0 \%)$ & $<0.01$ \\
\hline \multicolumn{4}{|l|}{ Metformin therapy } \\
\hline Yes & $(n=39) 319.5 \pm 194.1(266.1)$ & $(n=89) 493.2 \pm 296.1(410.0)$ & $<0.01$ \\
\hline No & $(n=15) 312.9 \pm 272.1(222.0)$ & $(n=11) 535.9 \pm 273.6(480.1)$ & 0.03 \\
\hline$p$ values ${ }^{5}$ & 0.44 & 0.55 & \\
\hline \multicolumn{4}{|l|}{ Statin therapy } \\
\hline 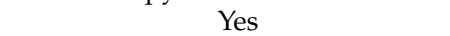 & $(n=26) 358.2 \pm 289.6(251.0)$ & $(n=71) 516.5 \pm 303.1(440.7)$ & $<0.01$ \\
\hline No & $(n=28) 321.5 \pm 249.6(275.0)$ & $(n=29) 452.4 \pm 264.9(349.0)$ & 0.02 \\
\hline$p$ values ${ }^{5}$ & $0 . \overline{5}$ & $0 . \overline{15}$ & \\
\hline \multicolumn{4}{|l|}{ Metformin + Statin therapy } \\
\hline Yes & $(n=21) 331.9 \pm 179.5(252.6)$ & $(n=64) 506.3 \pm 307.8(437.8)$ & 0.01 \\
\hline No & $(n=33) 307.9 \pm 244.7(243.1)$ & $(n=36) 483.0 \pm 267.3(367.3)$ & $<0.01$ \\
\hline$p$ values ${ }^{5}$ & 0.26 & 0.60 & \\
\hline
\end{tabular}

Table 3. Levels of metabolic biomarkers after stratifying by serum vitamin B-12 ${ }^{1}$.

\begin{tabular}{|c|c|c|c|c|}
\hline & \multicolumn{2}{|c|}{ Vegetarians $(n=54)$} & \multicolumn{2}{|c|}{ Omnivores $(n=100)$} \\
\hline & $\begin{array}{c}\leqslant 250 \mathrm{pmol} / \mathrm{L} \\
\quad(n=25)\end{array}$ & $\begin{array}{c}>250 \mathrm{pmol} / \mathrm{L} \\
\quad(n=29)\end{array}$ & $\begin{array}{c}\leqslant 250 \mathrm{pmol} / \mathrm{L} \\
(n=15)\end{array}$ & $\begin{array}{c}>250 \mathrm{pmol} / \mathrm{L} \\
\quad(n=85)\end{array}$ \\
\hline \multicolumn{5}{|l|}{ Blood glucose } \\
\hline fasting glucose (mmol/L) & $7.3 \pm 1.8(6.8)$ & $6.5 \pm 1.5(6.3) *+$ & $7.6 \pm 1.5(8.1)$ & $7.1 \pm 1.5(7.1)$ \\
\hline $\mathrm{HbA} 1 \mathrm{c}(\%)$ & $7.5 \pm 1.1(7.2)$ & $6.8 \pm 0.8(6.8)^{*, \dagger}$ & $7.3 \pm 0.8(7.5)$ & $7.2 \pm 0.8(7.2)$ \\
\hline \multicolumn{5}{|l|}{ Lipid profiles } \\
\hline $\mathrm{TC}(\mathrm{mmol} / \mathrm{L})$ & $4.2 \pm 0.8(4.1)$ & $4.6 \pm 0.9(4.6)$ & $4.2 \pm 0.7(4.2)$ & $4.7 \pm 0.8(4.7)^{*}$ \\
\hline TG $(\mathrm{mmol} / \mathrm{L})$ & $1.4 \pm 0.7(1.3)$ & $1.8 \pm 1.7(1.3)$ & $1.0 \pm 0.4(1.0)$ & $1.5 \pm 1.4(1.1)$ \\
\hline LDL-C (mmol/L) & $2.1 \pm 0.5(2.2)$ & $2.4 \pm 0.6(2.3)$ & $2.1 \pm 0.6(2.0)$ & $2.4 \pm 0.6(2.4)^{*}$ \\
\hline HDL-C (mmol/L) & $1.3 \pm 0.4(1.2)$ & $1.3 \pm 0.4(1.2)^{\dagger}$ & $1.5 \pm 0.4(1.4)$ & $1.4 \pm 0.3(1.4)$ \\
\hline TC/HDL-C & $3.4 \pm 0.8(3.1)$ & $3.8 \pm 1.3(3.6)$ & $2.9 \pm 0.7(2.6)$ & $3.5 \pm 1.0(3.3)$ \\
\hline Apo-A1 (g/L) & $1.2 \pm 0.3(1.3)$ & $1.3 \pm 0.4(1.3)$ & $1.2 \pm 0.3(1.2)$ & $1.2 \pm 0.3(1.2)$ \\
\hline Apo-B (g/L) & $0.8 \pm 0.2(0.8)$ & $0.9 \pm 0.3(0.9)$ & $0.7 \pm 0.2(0.7)$ & $0.8 \pm 0.3(0.8)$ \\
\hline
\end{tabular}

${ }^{1}$ mean $\pm \mathrm{SD}$ (medians); ${ }^{*}$ values were compared within groups; ${ }^{\dagger}$ values were compared between vegetarian and omnivore groups at the same stratified level of serum vitamin B-12.

\subsection{Levels of Oxidative Stress and Inflammatory Markers after Stratifying by Serum Vitamin B-12}

The levels of oxidative stress and inflammatory markers after stratifying by serum vitamin B-12 are shown in Table 4. The diabetic vegetarians with higher levels of vitamin B-12 had significantly higher antioxidant enzyme activity (CAT, $p<0.05)$ than those with lower levels of vitamin B-12. The diabetic omnivores with higher levels of vitamin B-12 had significantly lower oxidative stress (MDA, $p=0.06$ ) and inflammation (IL-6, $p=0.04$ ) than those with lower levels of vitamin B-12 and the vegetarians (MDA, $p=0.01$; hs-CRP, $p=0.03$; IL- $6, p=0.02$ ). The diabetic omnivores with higher levels of vitamin B-12 had significantly higher antioxidant enzyme activity (SOD, $p=0.04$ ) than the vegetarians. 
Table 4. Levels of oxidative stress and inflammatory markers after stratifying by serum vitamin B-12 ${ }^{1}$.

\begin{tabular}{|c|c|c|c|c|}
\hline & \multicolumn{2}{|c|}{ Vegetarians $(n=54)$} & \multicolumn{2}{|c|}{ Omnivores $(n=100)$} \\
\hline & $\begin{array}{c}\leqslant 250 \mathrm{pmol} / \mathrm{L} \\
(n=25)\end{array}$ & $\begin{array}{c}>250 \mathrm{pmol} / \mathrm{L} \\
(n=29)\end{array}$ & $\begin{array}{c}\leqslant 250 \mathrm{pmol} / \mathrm{L} \\
(n=15)\end{array}$ & $\begin{array}{c}>250 \mathrm{pmol} / \mathrm{L} \\
(n=85)\end{array}$ \\
\hline \multicolumn{5}{|l|}{ Oxidative stress } \\
\hline $\operatorname{MDA}(\mu \mathrm{mol} / \mathrm{L})$ & $1.6 \pm 0.6(1.3)$ & $1.6 \pm 0.3(1.6)$ & $1.5 \pm 0.3(1.5)$ & $1.4 \pm 0.3(1.4)^{*, \dagger}$ \\
\hline Ox-LDL-C (U/L) & $33.7 \pm 8.2(31.1)$ & $31.0 \pm 4.7(31.7)$ & $31.8 \pm 10.9(28.1)$ & $33.57 \pm 7.2(33.1)$ \\
\hline \multicolumn{5}{|l|}{ Antioxidant enzymes } \\
\hline CAT (U/mg protein) & $19.2 \pm 6.8(19.1)$ & $24.6 \pm 10.8(22.0) *$ & $19.3 \pm 5.9(18.0)$ & $25.5 \pm 12.4(22.4)$ * \\
\hline SOD (U/mg protein) & $18.4 \pm 8.1(17.0)$ & $14.5 \pm 5.7(14.9)$ & $19.6 \pm 7.8(23.1)$ & $19.6 \pm 7.9(18.6)^{\dagger}$ \\
\hline GPx (U/mg protein) & $20.0 \pm 4.3(19.5)$ & $20.5 \pm 4.9(20.5)$ & $21.2 \pm 4.1(21.6)$ & $20.1 \pm 5.1(19.8)$ \\
\hline \multicolumn{5}{|l|}{ Inflammatory markers } \\
\hline hs-CRP (mg/L) & $1.5 \pm 1.5(0.9)$ & $2.7 \pm 3.2(1.5)$ & $1.4 \pm 1.6(0.8)$ & $1.2 \pm 1.2(0.8)^{\dagger}$ \\
\hline IL-6 (pg/mL) & $2.2 \pm 1.7(1.7)$ & $2.7 \pm 2.2(1.8)$ & $2.4 \pm 1.7(2.0)$ & $1.5 \pm 0.8(1.3)^{*, \dagger}$ \\
\hline
\end{tabular}

3.5. Correlations between Serum Vitamin B-12 Status and Blood Glucose, Oxidative Stress, and Inflammatory Markers

The correlations between serum vitamin B-12 status and blood glucose, oxidative stress, and inflammatory markers are shown in Table 5 . A significant association was found between vitamin B-12 status and fasting glucose $(r=-0.17, p=0.03), \mathrm{HbA1c}(r=-0.33, p=0.02)$, oxidative stress (oxidized low density lipoprotein-cholesterol, $r=-0.19, p=0.03$ ), and antioxidant enzyme activity (catalase, $r=0.28, p=0.01$ ) in the diabetic vegetarians; vitamin B-12 status was significantly correlated with inflammatory markers (interleukin-6, $r=-0.33, p<0.01$ ) in diabetic omnivores. The similar trends of correlations between vitamin B-12 status and blood glucose, oxidative stress, and inflammatory markers additionally adjustment for gender and age (data not shown).

Table 5. Correlations between serum vitamin B-12 status ${ }^{1}$ and blood glucose, oxidative stress, and inflammatory markers.

\begin{tabular}{|c|c|c|c|}
\hline & Vegetarians $(n=54)$ & Omnivores $(n=100)$ & Pooled $(n=154)$ \\
\hline & \multicolumn{3}{|c|}{$r^{2}(p$ Values $)$} \\
\hline \multicolumn{4}{|l|}{ Blood glucose } \\
\hline fasting glucose (mmol/L) & $-0.17(0.03)$ & $-0.12(0.05)$ & $-0.10(0.03)$ \\
\hline HbA1c $(\%)$ & $-0.33(0.02)$ & $-0.06(0.35)$ & $-0.17(<0.01)$ \\
\hline \multicolumn{4}{|l|}{ Oxidative stress } \\
\hline $\operatorname{MDA}(\mu \mathrm{mol} / \mathrm{L})$ & $0.07(0.63)$ & $-0.11(0.06)$ & $-0.07(0.17)$ \\
\hline Ox-LDL-C (U/L) & $-0.19(0.03)$ & $0.09(0.42)$ & $0.00(0.98)$ \\
\hline \multicolumn{4}{|l|}{ Antioxidant enzymes } \\
\hline CAT (U /mg protein) & $0.28(0.01)$ & $0.17(0.03)$ & $0.23(<0.01)$ \\
\hline SOD (U/mg protein) & $-0.21(0.12)$ & $0.00(0.98)$ & $-0.03(0.70)$ \\
\hline GPx (U/mg protein) & $0.06(0.68)$ & $-0.08(0.43)$ & $-0.02(0.78)$ \\
\hline \multicolumn{4}{|l|}{ Inflammation } \\
\hline hs-CRP (mg/L) & $0.19(0.17)$ & $-0.05(0.41)$ & $0.03(0.69)$ \\
\hline $\mathrm{IL}-6(\mathrm{pg} / \mathrm{mL})$ & $0.13(0.37)$ & $-0.33(<0.01)$ & $-0.14(0.02)$ \\
\hline
\end{tabular}

${ }^{1}$ serum vitamin B-12 levels $>250 \mathrm{pmol} / \mathrm{L}$ defined as $1 ; \leqslant 250 \mathrm{pmol} / \mathrm{L}=0 ;{ }^{2}$ correlation coefficients.

\section{Discussion}

Mounting evidence has shown that the health benefits of a vegetarian diet in diabetic patients can provide a range of natural products and food forms of benefit for blood glucose and lipid abnormalities in diabetes [19-23]. However, in the present study, we found that diabetic vegetarians 
had a significantly lower vitamin B-12 status, which might be related to an increase the levels of oxidative stress and inflammation. Vitamin B-12 could potentially be a useful antioxidant, because it can stimulate methionine synthase activity and direct reaction with reactive oxygen and nitrogen species, and through a glutathione sparing effect, can modify signaling molecules to decrease oxidative stress [10-14,24,25]. In addition, vitamin B-12 could also act as an anti-inflammation agent through the mechanisms of down regulation of the transcription factor nuclear factor-kappa B (NF-kB), inhibition of nitric oxide synthase, and promotion of oxidative phosphorylation [25-27]. In the present study, we have examined inflammatory and metabolic profiles in patients with vitamin B12 deficiency and without vitamin B12 deficiency, regardless of their dietary habits (data not shown). Diabetic patients with lower vitamin B-12 status had a significantly higher levels of blood glucose $(\mathrm{HbA1c}, p=0.08)$ and inflammation (hs-CRP, $p=0.03$ ), and significantly lower antioxidant enzymes activity (CAT, $p=0.02$ and GPx, $p<0.01$ ) than those with higher vitamin B-12 status. It appears that if diabetic vegetarians are at a high risk for vitamin B-12 deficiency may increase risk of having lower antioxidant capacity and higher inflammatory status. Thus, we suggest it is necessary to monitor vitamin B-12 status regularly in diabetic vegetarians.

Metformin, the first line drug for treating diabetes, has been reported to potentially decrease vitamin B-12 status [3-5]. We observed a lower vitamin B-12 status in the diabetic omnivores under metformin therapy, but that was not reached statistically significant (Table 2), therefore, in this study, we consider a vegetarian diet might be a major cause of vitamin B-12 deficiency. The dietary reference intakes (DRIs) of vitamin B-12 in Taiwan are similar to those of the Institute of Medicine (IOM) in the USA and is $2.4 \mu \mathrm{g}$ per day. Vegetarians, lack the rich vitamin B-12 source of animal food, and although our vegetarian subjects were included lacto- and ovo-vegetarians, the median intake of vitamin B-12 was still lower $(0.2 \mu \mathrm{g} /$ day, Table 1$)$ than the DRIs. The dietary guideline for vegetarians in Taiwan suggest that vegetarians could consume plant food containing substantial amounts of vitamin B-12, such as edible algae (dried green and purple lavers) to meet the recommendation dietary intake of vitamin B-12. However, algal vitamin B-12 appears to be inactive in humans [27]. Although we did not find a significantly lower vitamin B-12 status in diabetic patients under metformin therapy, there is enough scientific evidence to recommend the supplementation of vitamin B-12 in diabetes who are being treated with metformin, to reduce the risk of developing neuropathy and its consequences [28]. As a result, we support that patients with diabetes, particularly those adhering to a vegetarian diet should intake vitamin B-12 supplements or vitamin B-12 fortified food could maintain adequate vitamin B-12 status and prevent vitamin B-12 deficiency.

Vitamin B-12 plays a dominant role in the utilization of carbohydrates, and a lower vitamin B-12 status may cause hyperglycemia. In vitro experiments have indicated that the level of glutathione as well as enzyme activity are lower in vitamin B-12 deficient animals; as a result, vitamin B-12 is beneficial for the regulation of glucose [29]. Some observation studies from India have shown that a lower vitamin B-12 status during pregnancy was associated with higher maternal and off-spring insulin resistance [30-34]. Those results are also supported in our diabetic subjects; we found the levels of fasting glucose and $\mathrm{HbA1c}$ were significantly lower in the diabetic vegetarians who had a higher vitamin B-12 status (Table 3), and vitamin B-12 status was significantly negatively correlated with blood glucose, particularly in diabetic vegetarians (Table 5). Because a lower vitamin B-12 status may correlate with impaired glucose tolerance, it is important to monitor vitamin B-12 status in patients with diabetes, particularly those adhering to a vegetarian diet. With regard to the association between vitamin B-12 status and lipid profiles, in an observation study of diabetes subjects from Europe and India, the authors found a negative association between vitamin B-12 and lipid profiles [34]. However, in the present study, we found diabetic omnivores with higher vitamin B-12 status had higher levels of lipid profiles (TC and LDL-C) than those with lower vitamin B-12 status (Table 3); we consider vitamin B-12 status to be positively correlated with lipid profiles, which might be due to animal food containing more fat. 
The strength of this study was that it was the first clinical study to investigate the correlation between vitamin B-12 status and oxidative stress, and inflammation in diabetic vegetarians and omnivores. Vitamin B-12 status is significantly correlated with oxidative stress and inflammation in the present study. Because vegetarians are at a higher risk for vitamin B-12 deficiency, that might negate the health benefits of a vegetarian diet for those with diabetes. We suggest that diabetic vegetarians should monitor their vitamin B-12 status regularly and use vitamin B-12 supplements if necessary. Further interventional studies are needed to explore the proper dosage of vitamin B-12 supplements for lower oxidative stress and inflammation in patients with diabetes adhering to a vegetarian diet.

\section{Conclusions}

Vitamin B-12 status is significantly negatively correlated with the levels of blood glucose, oxidative stress (ox-LDL) and positively correlated with antioxidant enzyme activity in diabetic vegetarians; and significantly negatively correlated with the levels of inflammation in diabetic omnivores. We suggest it is necessary to monitor the levels of vitamin B-12 in patients with diabetes, particularly those adhering to a vegetarian diet.

Acknowledgments: This study was supported by a grant from the Chung Shan Medical University (CSMU-INT-104-05), Taiwan. We would like to express our sincere appreciation to the subjects for their participation. We would also like to thank the nurses and dietitians at Lee's Endocrinologic Clinic for providing expert assistance in blood sample and diet record recall collection.

Author Contributions: Y.J.L. and P.T.L. conceived and designed the study. M.Y.W. and M.C.L. helped to conduct the study and sample analyses. P.T.L. performed the data analyses and wrote the manuscript. All authors read and approved the final manuscript.

Conflicts of Interest: The authors declare no conflict of interest.

\section{Abbreviations}

The following abbreviations are used in this manuscript:

\begin{tabular}{|c|c|}
\hline $\mathrm{HbA1c}$ & glycohemoglobin \\
\hline Apo & apolipoprotein \\
\hline CAT & catalase \\
\hline FG & fasting glucose \\
\hline GPx & glutathione peroxidase \\
\hline HDL-C & high density lipoprotein-cholesterol \\
\hline hs-CRP & high sensitivity C-reactive protein \\
\hline IL-6 & high sensitivity interleukin-6 \\
\hline LDL-C & low density lipoprotein-cholesterol \\
\hline MDA & malondialdehyde \\
\hline SOD & superoxide dismutase \\
\hline $\mathrm{TC}$ & total cholesterol \\
\hline TG & triglycerol \\
\hline Ox-LDL-C & oxidized low density lipoprotein-cholesterol \\
\hline
\end{tabular}

\section{References}

1. Evatt, M.; Terry, P.D.; Ziegler, T.R.; Oakley, G.P. Association between vitamin B12-containing supplement consumption and prevalence of biochemically defined B12 deficiency in adults in NHANES III (third national health and nutrition examination survey). Public Health Nutr. 2010, 13, 25-31. [CrossRef] [PubMed]

2. Pawlak, R. Is vitamin B12 deficiency a risk factor for cardiovascular disease in vegetarians? Am. J. Prev. Med. 2015, 48, e11-e26. [CrossRef] [PubMed]

3. DeFronzo, R.A.; Goodman, A.M. The Multicenter Metformin Study Group. Efficacy of metformin in patients with non-insulin-dependent diabetes mellitus. N. Engl. J. Med. 1995, 333, 541-549. [CrossRef] [PubMed] 
4. De Jager, J.; Kooy, A.; Lehert, P.; Wulffelé, M.G.; van der Kolk, J.; Bets, D.; Verburg, J.; Donker, A.J.; Stehouwer, C.D. Long term treatment with metformin in patients with type 2 diabetes and risk of vitamin B-12 deficiency: Randomised placebo controlled trial. BMJ 2010, 340, c2181. [CrossRef] [PubMed]

5. Reinstatler, L.; Qi, Y.P.; Williamson, R.S.; Garn, J.V.; Oakley, G.P., Jr. Association of biochemical B $B_{12}$ deficiency with metformin therapy and vitamin $B_{12}$ supplements: The National Health and Nutrition Examination Survey, 1999-2006. Diabetes Care 2012, 35, 327-333. [CrossRef] [PubMed]

6. Rains, J.L.; Jain, S.K. Oxidative stress, insulin signaling, and diabetes. Free Radic. Biol. Med. 2011, 50, 567-575. [CrossRef] [PubMed]

7. Al-Maskari, M.Y.; Waly, M.I.; Ali, A.; Al-Shuaibi, Y.S.; Ouhtit, A. Folate and vitamin B12 deficiency and hyperhomocysteinemia promote oxidative stress in adult type 2 diabetes. Nutrition 2012, 28, e23-e26. [CrossRef] [PubMed]

8. Birch, C.S.; Brasch, N.E.; McCaddon, A.; Williams, J.H. A novel role for vitamin B (12): Cobalamins are intracellular antioxidants in vitro. Free Radic. Biol. Med. 2009, 47, 184-188. [CrossRef] [PubMed]

9. Solomon, L.R. Functional cobalamin (vitamin B12) deficiency: Role of advanced age and disorders associated with increased oxidative stress. Eur. J. Clin. Nutr. 2015, 69, 687-692. [CrossRef] [PubMed]

10. Kräutler, B. Vitamin B12: Chemistry and biochemistry. Biochem. Soc. Trans. 2005, 33, 806-810. [CrossRef] [PubMed]

11. Ling, C.T.; Chow, B.F. Effect of vitamin B12 on the levels of soluble sulfhydryl compounds in blood. J. Biol. Chem. 1953, 202, 445-446. [PubMed]

12. McCaddon, A.; Regland, B.; Hudson, P.; Davies, G. Functional vitamin B12 deficiency and Alzheimer disease. Neurology 2002, 58, 1395-1399. [CrossRef] [PubMed]

13. Veber, D.; Mutti, E.; Tacchini, L.; Gammella, E.; Tredici, G.; Scalabrino, G. Indirect down-regulation of nuclear NF-kappaB levels by cobalamin in the spinal cord and liver of the rat. J. Neurosci. Res. 2008, 86, 1380-1387. [CrossRef] [PubMed]

14. Botsoglou, N.A. Rapid, sensitive, and specific thiobarbituric acid method for measuring lipid peroxidation in animal tissue, food and feedstuff samples. J. Agric. Food Chem. 1994, 42, 1931-1937. [CrossRef]

15. Aebi, H. Catalase in vitro. Methods Enzymol. 1984, 105, 121-126. [PubMed]

16. Marklund, S.; Marklund, G. Involvement of superoxide anion radical in autoxidation of pyrogallol and a convenient assay for superoxide dismutase. Eur. J. Biochem. 1974, 47, 469-474. [CrossRef] [PubMed]

17. Paglia, D.; Valentine, W. Studies on the qualitative characterization of erythrocyte glutathione peroxidase. J. Lab. Clin. Med. 1967, 70, 159-169.

18. Barnard, N.D.; Katcher, H.I.; Jenkins, D.J.; Cohen, J.; Turner-McGrievy, G. Vegetarian and vegan diets in type 2 diabetes management. Nutr. Rev. 2009, 67, 255-263. [CrossRef] [PubMed]

19. Jenkins, D.J.; Kendall, C.W.; Marchie, A.; Jenkins, A.L.; Augustin, L.S.; Ludwig, D.S.; Barnard, N.D.; Anderson, J.W. Type 2 diabetes and the vegetarian diet. Am. J. Clin. Nutr. 2003, 78, 610S-616S. [PubMed]

20. Kahleova, H.; Pelikanova, T. Vegetarian diets in the prevention and treatment of type 2 diabetes. J. Am. Coll. Nutr. 2015, 27, 1-11. [CrossRef] [PubMed]

21. Sabaté, J.; Wien, M. A perspective on vegetarian dietary patterns and risk of metabolic syndrome. Br. J. Nutr. 2015, 113, S136-S143. [CrossRef] [PubMed]

22. Tonstad, S.; Butler, T.; Yan, R.; Fraser, G.E. Type of vegetarian diet, body weight, and prevalence of type 2 diabetes. Diabetes Care 2009, 32, 791-796. [CrossRef] [PubMed]

23. Manzanares, W.; Hardy, G. Vitamin B12: The forgotten micronutrient for critical care. Curr. Opin. Clin. Nutr. Metab. Care 2010, 13, 662-668. [CrossRef] [PubMed]

24. Wheatley, C. A scarlet pimpernel for the resolution of inflammation? The role of supra-therapeutic doses of cobalamin, in the treatment of systemic inflammatory response syndrome (SIRS), sepsis, severe sepsis, and septic or traumatic shock. Med. Hypotheses 2006, 67, 124-142. [CrossRef] [PubMed]

25. Dagnelie, P.C.; van Staveren, W.A.; van den Berg, H. Vitamin B-12 from algae appears not to be bioavailable. Am. J. Clin. Nutr. 1991, 53, 695-697. [PubMed]

26. Wheatley, C. The return of the Scarlet Pimpernel: Cobalamin in inflammation II-Cobalamins can both selectively promote all three nitric oxide synthases (NOS), particularly iNOS and eNOS, and, as needed, selectively inhibit iNOS and nNOS. J. Nutr. Environ. Med. 2007, 16, 181-211. [CrossRef] [PubMed]

27. Watanabe, F. Vitamin B12 sources and bioavailability. Exp. Biol. Med. 2007, 232, 1266-1274. [CrossRef] [PubMed] 
28. Valdés-Ramos, R.; Guadarrama-López, A.L.; Martínez-Carrillo, B.E.; Benítez-Arciniega, A.D. Vitamins and type 2 diabetes mellitus. Endocr. Metab. Immune Disord. Drug Targets 2015, 15, 54-63. [CrossRef] [PubMed]

29. Chow, B.F.; Stone, H.H. The relationship of vitamin B12 to carbohydrate metabolism and diabetes mellitus. Am. J. Clin. Nutr. 1957, 5, 431-439. [PubMed]

30. Krishnaveni, G.V.; Hill, J.C.; Veena, S.R.; Bhat, D.S.; Wills, A.K.; Karat, C.L.; Yajnik, C.S.; Fall, C.H. Low plasma vitamin B12 in pregnancy is associated with gestational "diabesity" and later diabetes. Diabetologia 2009, 52, 2350-2358. [CrossRef] [PubMed]

31. Knight, B.A.; Shields, B.M.; Brook, A.; Hill, A.; Bhat, D.S.; Hattersley, A.T.; Yajnik, C.S. Lower Circulating B12 is associated with higher obesity and insulin resistance during pregnancy in a non-diabetic white British population. PLoS ONE 2015, 10, e0135268. [CrossRef] [PubMed]

32. Yajnik, C.S.; Deshpande, S.S.; Jackson, A.A.; Refsum, H.; Rao, S.; Fisher, D.J.; Bhat, D.S.; Naik, S.S.; Coyaji, K.J.; Joglekar, C.V.; et al. Vitamin B12 and folate concentrations during pregnancy and insulin resistance in the offspring: The Pune Maternal Nutrition Study. Diabetologia 2008, 51, 29-38. [CrossRef] [PubMed]

33. Stewart, C.P.; Christian, P.; Schulze, K.J.; Arguello, M.; LeClerq, S.C.; Khatry, S.K.; West, K.P., Jr. Low maternal vitamin B-12 status is associated with offspring insulin resistance regardless of antenatal micronutrient supplementation in rural Nepal. J. Nutr. 2011, 141, 1912-1917. [CrossRef] [PubMed]

34. Adaikalakoteswari, A.; Jayashri, R.; Sukumar, N.; Venkataraman, H.; Pradeepa, R.; Gokulakrishnan, K.; Anjana, R.M.; McTernan, P.G.; Tripathi, G.; Patel, V.; et al. Vitamin B12 deficiency is associated with adverse lipid profile in Europeans and Indians with type 2 diabetes. Cardiovasc. Diabetol. 2014, 13, 129. [CrossRef] [PubMed]

(C) 2016 by the authors; licensee MDPI, Basel, Switzerland. This article is an open access article distributed under the terms and conditions of the Creative Commons by Attribution (CC-BY) license (http://creativecommons.org/licenses/by/4.0/). 